\title{
Optimal treatment strategy using appropriate use criteria
}

\section{Krešimir Gabaldo*, Đeiti Prvulović, Božo Vujeva, Irzal Hadžibegović}

General Hospital "Dr. Josip Benčević", Slavonski Brod, Croatia

\section{RECEIVED:}

July 29, 2015

ACCEPTED:

September 17, 2015

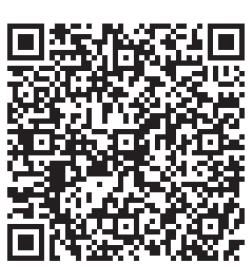

KEYWORDS: coronary revascularization, acute coronary syndrome, stable coronary disease. CITATION: Cardiol Croat. 2015;10(9-10):234. | DOI: http://dx.doi.org/10.15836/ccar.2015.234

*ADDRESS FOR CORRESPONDENCE: Opća bolnica „Dr. Josip Benčević“, Štampareva 42, HR-35000 Slavonski Brod, Croatia. / Phone: +385-98-139-8810 / E-mail: kresimir.gabaldo@sb.t-com.hr

ORCID: Krešimir Gabaldo, http://orcid.org/0000-0002-0116-5929 • Božo Vujeva, http://orcid.org/0000-0003-0490-3832 Đeiti Prvulović, http://orcid.org/0000-0002-8041-1197 • Irzal Hadžibegović, http://orcid.org/0000-0002-3768-9134

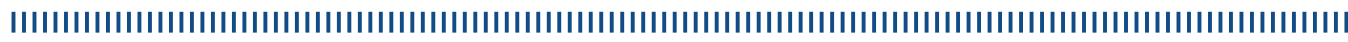

INTRODUCTION: Coronary atherosclerotic heart disease is the leading cause of death worldwide. The clinical presentation of the disease is extremely variable - from mild chronic and asymptomatic disease to acute and life threatening. The appropriate use criteria (AUC) for coronary revascularization is a new tool to help cardiologists with clinical decision making. ${ }^{1}$ The criteria are based on the clinical presentation, severity of symptoms, extent of ischemia on non-invasive testing, risk assessment, use of anti-ischemic therapy and coronary anatomy. The Technical panel scored the clinical scenarios on a scale 1-9. Scores of 7-9 indicate that revascularization is appropriate, while scores 1-3 indicate inappropriate revascularization.

PATIENTS AND METHODS: We analyzed 20 patients who have undergone coronary angiography and PCI. 10 patients were with stable coronary artery disease and 10 were acute coronary syndrome patients. In decision making we used SCAI Quality Improvement Toolkit. In a group of stabile coronary artery disease we found 7 patients to be appropriate to revascularize. Among them we performed ad hoc PCI on 3 patients, staged PCI on 3 patients, 1 patient was referred for CABG, while 3 patients were uncertain for revascularization and we put them on optimal medical therapy. In a group of ACS patients all 10 patients were appropriate for revascularization, in 7 patients we performed ad hoc PCI, in 2 patients we did staged PCI, while 1 patient was referred to CABG.

CONCLUSION: The appropriate use criteria (AUC) for coronary revascularization is a tool to help cardiologists, not a threat. As a general rule, patients with ACS are usually appropriate for cardiac catheterization and PCI, while asymptomatic patients, particularly those without noninvasive testing are inappropriate. The main issue of AUC is to question your own judgment and improve your current practice. 